\title{
PERHITUNGAN EFISIENSI BOILER DENGAN METODE SECARA LANGSUNG PADA BOILER PIPA API
}

\author{
Agus Sugiharto \\ PPSDM MIGAS, Cepu
}

\begin{abstract}
ABSTRAK
Pasokan energi merupakan hal yang sangat penting bagi kehidupan manusia sehari - hari terutama pada kegiatan industri. Meningkatnya kebutuhan energi tersebut menyebabkan naiknya kapasitas tambahan daya di seluruh dunia khususnya pembangkit uap. Pembangkit uap inilah yang memberikan suplai kepada proses pembangkitan listrik terbesar saat ini, disamping uap banyak juga digunakan untuk proses di industri lainnya seperti industri migas, kimia, manufaktur dan sebagainya. Seiring dengan semakin tingginya kebutuhan uap maka perlu dipikirkan cara untuk menaikkan efisiensi pada boiler. Dengan semakin efisiennya boiler, akan berdampak secara langsung terhadap biaya proses, meminimalkan polusi lingkungan dan pelepasan gas berbahaya kedalam lingkungan. Boiler yang efisien akan menjadi kebutuhan yang sangat vital bagi kehidupan industri di masa yang akan datang.
\end{abstract}

Kata kunci: Boiler pipa api, efisiensi, metode secara langsung

\section{PENDAHULUAN}

Boiler adalah bejana tertutup yang digunakan untuk menghasilkan uap bertekanan, dimana uap bertekanan yang dihasilkan dipergunakan diluar boiler itu sendiri. Uap yang dihasilkan dari boiler ini pada umumnya berasal dari proses pembakaran yang menggunakan bahan bakar gas, cair maupun bahan bakar padat. Pada industri migas uap bertekanan yang dihasilkan bisa digunakan untuk proses pembangkitan listrik, proses di kilang, pemanas, steam flooding dan sebagainya.

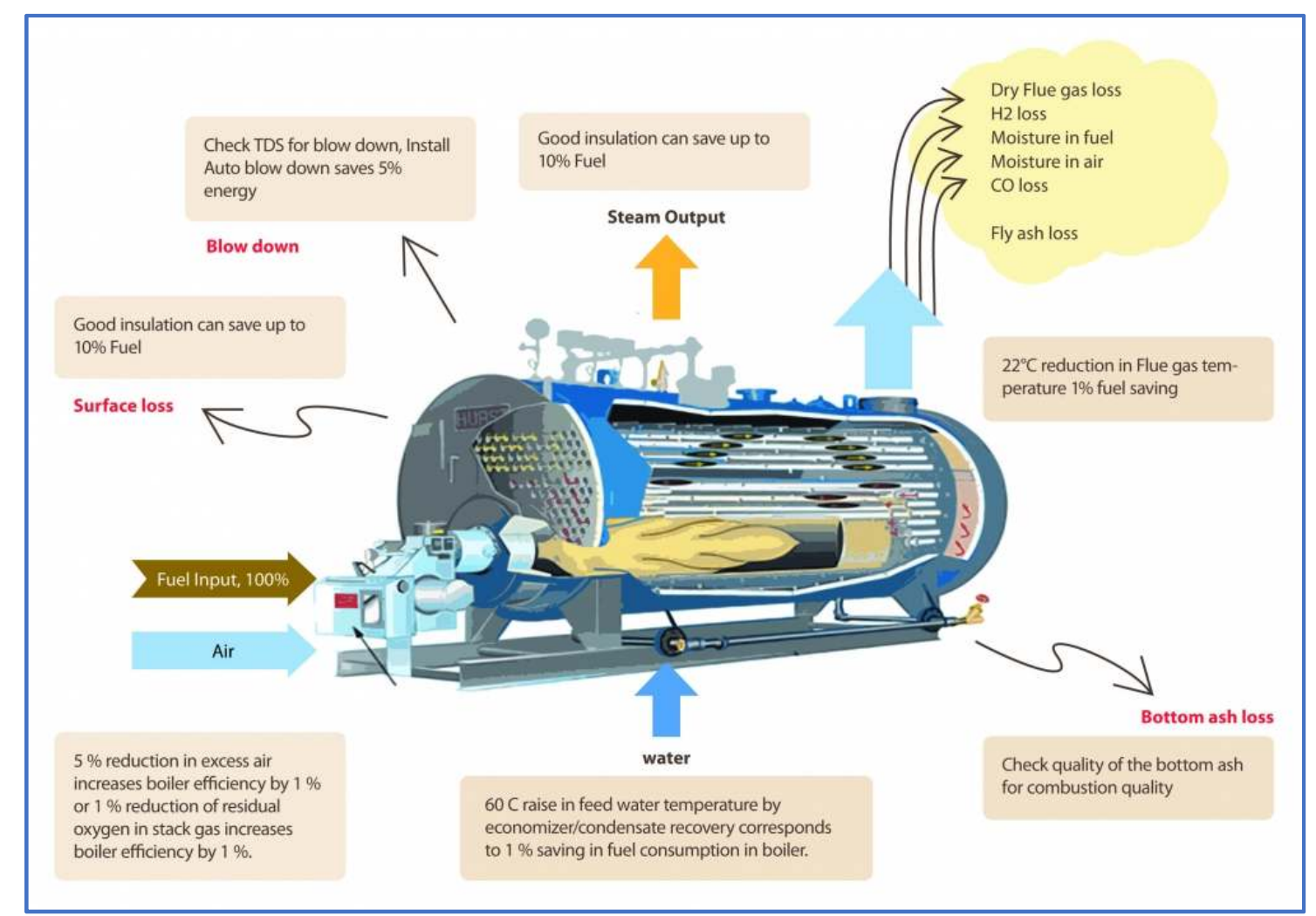

Gambar 1. Sistem Operasi Pada Boiler 
Efisiensi boiler adalah sebuah besaran yang menunjukkan hubungan antara supply energi masuk ke dalam boiler dengan energi keluaran yang dihasilkan oleh boiler. Efisiensi Pembakaran Boiler secara umum menjelaskan kemampuan sebuah burner untuk membakar keseluruhan bahan bakar yang masuk ke dalam ruang bakar (furnace) boiler. Efisiensi boiler dihitung dari jumlah bahan bakar yang tidak terbakar bersamaan dengan jumlah udara sisa pembakaran (excess air). Pembakaran boiler dapat dikatakan efisien apabila tidak ada bahan bakar yang tersisa di ujung keluaran ruang bakar boiler, begitu pula dengan jumlah udara sisa.

Untuk mendapatkan efisiensi pembakaran yang tinggi, burner dan ruang bakar boiler harus didesain seoptimum mungkin. Di sisi lain perbedaan penggunaan jenis bahan bakar juga mempengaruhi efisiensi pembakaran. Diketahui bahwa bahan bakar cair (seperti solar dan residu) dan gas (seperti LNG dan LNG) menghasilkan efisiensi pembakaran yang lebih tinggi jika dibandingkan bahan bakar padat seperti batubara. Gambar 1. dibawah ini menunjukkan sistem operasi secara umum pada suatu boiler, dimana bahan bakar dan udara digunakan untuk memanaskan air umpan boiler yang akan menghasilkan steam atau uap bertekanan. Tetapi pada proses pembakaran ini tidak mungkin berlangsung secara sempurna mengingat adanya panas yang hilang selama proses pembakaran terjadi, seperti panas yang terbuang melalui stack atau cerobong asap, blow down, dan kehilangan panas di permukaan boiler.

\section{TINJAUAN PUSTAKA}

\section{A. EFISIENSI BOILER}

Perhitungan efisiensi pembakaran boiler dilakukan dengan menggunakan rumus seperti dibawah ini, dimana jumlah total energi panas yang dilepas oleh pembakaran dikurangi dengan energi panas yang lolos melewati stack (cerobong asap), dibagi dengan total energi panas.

$$
\eta \text { combustion }=\frac{\text { Qin }- \text { Qlosses }}{\text { Qin }} \times 100 \%
$$

dimana :

$\eta$ combustion : Efisiensi pembakaran boiler (\%)

$Q$ in $\quad$ : Energi panas total hasil pembakaran (kalori; Joule)

Q losses : Energi panas lolos melewati cerobong asap (kalori; Joule)

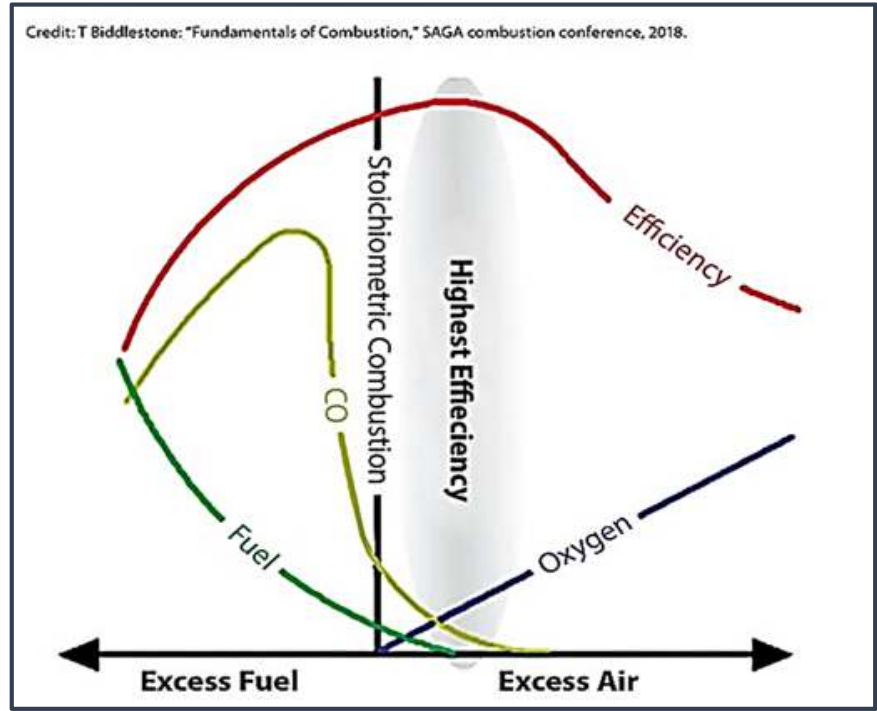

Gambar 2 Efisiensi Thermal Boiler 
Satu-satunya yang sulit dari efisiensi pembakaran adalah bagaimana mengejar angka yang paling optimal. Efisiensi pembakaran ditandai dengan terbakarnya keseluruhan bahan bakar di ruang bakar. Sedangkan parameter kontrol yang digunakan untuk memastikan keseluruhan bahan bakar terbakar, adalah jumlah udara sisa pembakaran (excess air) yang keluar melalui stack. Semakin banyak jumlah excess air yang keluar melewati cerobong asap, maka semakin kecil pula kemungkinan jumlah bahan bakar yang belum terbakar bisa melewati cerobong asap. Namun juga, semakin banyak jumlah excess air yang lolos melewati cerobong asap, jumlah energi panas yang lolos terbawa oleh udara sisa tersebut juga semakin banyak. Maka dari itu ada angka optimum dari besaran excess air, sehingga didapatkan efisiensi pembakaran boiler yang paling optimal.

Nampak pada ilustrasi grafik pada gambar 2 di atas bahwa semakin tinggi jumlah udara (oksigen) yang lolos melewati stack, maka akan semakin kecil jumlah bahan bakar termasuk karbon monoksida yang belum terbakar sempurna. Namun juga seperti yang telah kita bahas di atas, semakin tinggi jumlah excess air maka grafik efisiensi pembakaran kembali turun, tidak lain hal ini dikarenakan energi panas yang ikut lolos dengan udara sisa tersebut. Maka dapat dipastikan ada nilai paling optimum dari excess air sehingga didapatkan efisiensi pembakaran paling baik. Secara umum nilai excess air optimum untuk pembakaran gas alam (LPG dan LNG) adalah $3-15 \%$, bahan bakar cair di angka $3-15 \%$, dan $15-40 \%$ untuk pembakaran batubara. Oleh sebab itu penggunaan bahan bakar gas alam relatif jauh lebih bersih dibanding menggunakan bahan bakar jenis lainnya. Menurut Babcox \& Wilcox, a McDermott Company nilai dari excess air bisa dilihat pada gambar 3 dibawah ini.

\begin{tabular}{|lc|}
\hline \multicolumn{1}{c}{ Fuel } & Excess air, \% by weight \\
\hline Pulverized coal & $15-20$ \\
Coal & \\
Fluidized bed combustion & $15-20$ \\
Spreader stoker & $25-35$ \\
Water-cooled vibrating grate stoker & $25-35$ \\
Chain and traveling grate stoker & $25-35$ \\
Underfeed stoker & $25-40$ \\
Fuel oil & $3-15$ \\
Natural gas & $3-15$ \\
Coke oven gas & $3-15$ \\
Blast furnace gas & $15-30$ \\
Wood/bark & $20-25$ \\
Refuse-derived fuel (RDF) & $40-60$ \\
Municipal solid waste (MSW) & $80-100$ \\
\hline sourcs: Babcock \& Wilcox, a McDermott company: \\
\hline
\end{tabular}

Gambar 3 Range Excess Air Pada Beberapa Jenis Bahan Bakar Pada Boiler

\section{B. PERHITUNGAN EFISIENSI DENGAN METODE LANGSUNG}

Dikenal ada dua metode untuk menghitung efisiensi bahan bakar pada boiler, yaitu metode langsung dan metode tak langsung. Metode langsung, atau dikenal juga sebagai metode input-output, dilakukan dengan jalan membandingkan secara langsung energi panas yang diserap oleh air sehingga berubah fase menjadi uap air (energi output), dengan energi panas yang dihasilkan oleh pembakaran bahan bakar di dalam ruang bakar boiler (energi input).

Efisiensi ketel uap dinyatakan sebagai perbandingan panas sebenarnya yang digunakan untuk memanaskan air dan pembentukan uap terhadap panas hasil pembakaran bahan bakar di dalam dapur. Untuk mengetahui kinerja sebuah boiler tidak cukup hanya dengan mengetahui efisiensinya saja. Dengan mengetahui efisiensi boiler saja kita hanya dapat menyatakan bahwa ketel yang dievaluasi masih dapat bekerja dengan baik atau tidak, atau dapat juga dikatakan jika boiler mengalami penurunan efisiensi, masih 
dalam batas kewajaran atau tidak. Jadi jelas bahwa efisiensi hanya menunjukkan kemampuan untuk menyerap panas dari hasil pembakaran.

Rumusan sederhana dari perhitungan metode langsung adalah sebagai berikut:

$$
\begin{aligned}
\eta f u e l & =\frac{Q \text { steam }}{Q \text { fuel }} \times 100 \% \\
\eta f u e l & =\frac{Q x\left(h_{g}-h_{f}\right)}{q \times G C V} \times 100 \%
\end{aligned}
$$

dimana:

१fuel : Efisiensi bahan bakar boiler (\%)

Qsteam : Energi panas total yang diserap uap air (kalori; Joule)

$Q \quad$ : Debit uap air keluar boiler (kg/jam)

hg : Entalpi uap keluar boiler $(\mathrm{kcal} / \mathrm{kg})$

hf : Entalpi air masuk boiler $(\mathrm{kcal} / \mathrm{kg})$

Qfuel : Energi panas yang dihasilkan dari pembakaran bahan bakar (kalori; Joule)

$q \quad$ : Debit kebutuhan bahan bakar $(\mathrm{kg} / \mathrm{jam})$

GCV : Gross Calorific Value atau nilai kalor spesifik bahan bakar (kcal/kg)

Pada metode langsung, ada beberapa parameter yang harus diukur secara presisi agar didapatkan hasil perhitungan yang akurat. Parameter-parameter tersebut antara lain adalah:

1. Debit air (feedwater) masuk ke boiler

2. Tekanan dan temperatur keseluruhan aliran fluida air umpan (feed water) yang masuk kedalam boiler.

3. Debit kebutuhan bahan bakar yang digunakan ( $\mathrm{kg} / \mathrm{jam})$

4. Nilai kalor (heating value) bahan bakar ( $\mathrm{kcal} / \mathrm{kg})$

5. Energi masuk lainnya

\section{METODE PENELITIAN}

Studi pustaka dan lapangan menjadi metode yang digunakan dalam penulisan ini. Studi pustaka merupakan kajian teoritis, referensi, serta literatur ilmiah lainnya termasuk hasil penelitian sebelumnya untuk mendapatkan landasan teori terhadap permasalahan yang diteliti. Sedangkan studi lapangan menunjukkan data - data yang digunakan sebagai dasar perhitungan efisiensi boiler secara langsung.

\section{HASIL PENELITIAN DAN PEMBAHASAN}

Pada penelitian kali ini akan dihitung efisiensi boiler dengan menggunakan metode langsung. Dimana data yang digunakan adalah Boiler nomor 2 PPSDM MIGAS, dimana spesifikasi teknisnya adalah sebagai berikut :

- Tipe : fire tube (pipa api)

- Tahun Pembuatan : :2017

- Kapasitas maksimum : 6 ton/jam

- Tekanan Operasi $\quad: \pm 4 \mathrm{~kg} / \mathrm{cm}^{2}$

- Tekanan maksimal $\quad: \pm 10 \mathrm{~kg} / \mathrm{cm}^{2}$

- Temperatur Operasi $: \pm 130{ }^{\circ} \mathrm{C}$. 
- Temperatur Maksimal $: \pm 180{ }^{\circ} \mathrm{C}$.

Dari name plate diatas bisa diketahui bahwa boiler yang dioperasikan merupakan jenis fire tube dengan kategori kapasitas dan tekanan rendah. Data - data operasi harian boiler dapat kita lihat seperti dibawah ini:

1. Q : Debit uap air keluar boiler (kg/jam) sebesar $2237,25 \mathrm{~kg} / \mathrm{jam}$

2. hg : Entalpi uap keluar boiler $(\mathrm{kcal} / \mathrm{kg})$, temperatur uap $130^{\circ} \mathrm{C}$, dengan tekanan $4 \mathrm{~kg} / \mathrm{cm}^{2}$ : $656,362 \mathrm{kcal} / \mathrm{kg}$

3. hf : Entalpi air masuk boiler (kcal/kg), suhu air umpan $60^{\circ} \mathrm{C}$ : $60 \mathrm{kcal} / \mathrm{kg}$

4. q : Debit kebutuhan bahan bakar (kg/jam), jumlah bahan bakar $=179,7$ liter/jam, dijadikan satuan berat dengan nilai $\mathrm{SG} 60 / 60=0,9036$ (untuk MFO/residu), maka $\quad \mathrm{q}=179,7 \mathrm{x}$ $0,9036=162,38 \mathrm{~kg} / \mathrm{jam}$

5. GCV : Gross Calorific Value atau nilai kalor spesifik bahan bakar $(\mathrm{kcal} / \mathrm{kg})$ untuk residu atau HFO SEBESAR : $41 \mathrm{~kJ} / \mathrm{g}=41 \mathrm{MJ} / \mathrm{kg}=9799 \mathrm{kcal} / \mathrm{kg}$

Dari data harian diatas maka kita dapat menghitung Efisiensi boiler secara langsung.

$$
\begin{aligned}
& \eta f u e l=\frac{Q \times\left(h_{g}-h_{f}\right)}{q \times G C V} \times 100 \% \\
& \eta f u e l=\frac{2237 \mathrm{~kg} / \mathrm{jam} \times(656,362 \mathrm{kcal} / \mathrm{kg}-60 \mathrm{kcal} / \mathrm{kg})}{162,38 \mathrm{~kg} / \mathrm{jam} \times 9799 \mathrm{kcal} / \mathrm{kg}} \times 100 \% \\
& \eta f u e l=\frac{2237 \mathrm{~kg} / \mathrm{jam} \times(650 \mathrm{kcal} / \mathrm{kg}-60 \mathrm{kcal} / \mathrm{kg})}{162,38 \mathrm{~kg} / \mathrm{jam} \times 9799 \mathrm{kcal} / \mathrm{kg}} \times 100 \% \\
& \eta f u e l=83,84 \%
\end{aligned}
$$

Dari hasil perhitungan efisiensi boiler didapat angka sebesar 83,84\% sehingga kita bisa menyimpulkan bahwa boiler tersebut masih sangat baik dan layak digunakan. Sebenarnya semakin tinggi efisiensi boiler maka akan semakin baik kinerjanya.

\section{KESIMPULAN}

Dari hasil perhitungan efisiensi boiler dengan menggunakan metode secara langsung (direct method) PPSDM Migas sebesar 83,84 \%, hal ini menunjukkan bahwa kinerjanya masih sangat baik.

Sebenarnya untuk mengetahui nilai kinerja boiler secara lebih detail bisa menggunakan perhitungan dengan metode tidak langsung (indirect method), karena nilainya bisa mewakili keadaan operasi sebenarnya dengan komponen perhitungan yang lebih terperinci. Perhitungan secara tidak langsung belum bisa dilakukan karena keterbatasan data dukung yang dipunyai dan belum adanya beberapa peralatan ukur seperti flow meter untuk blow down, jumlah udara pembakaran dan lain - lain.

Untuk menaikkan nilai dari efisiensi boiler bisa dilakukan dengan perbaikan kinerja boiler dengan memasang peralatan seperti economizer dan air preheater.

\section{DAFTAR PUSTAKA}

Ahmad Mahmoudi Lahijani, Eris. E. Supeni and Fatemeh Kalantari, 2008, A Review of Indirect Method For Measuring Thermal Efficiency In Fire Tube Steam Boilers, Department of Mechanical Engineering, Faculty of Engineering, University Putra Malaysia, 43400 Serdang, Journal of Industrial Pollution Control 34(1)(2018) pp 1825-1832.

The American Society of Mechanical Engineers (ASME PTC 4-2008)

Eflita Yohana Dan Askhabulyamin, Perhitungan Efisiensi Dan Konversi Dari Bahan Bakar Solar Ke Gas Pada Boiler Ebara Hkl 1800 Ka, Jurnal Rotasi Jurusan Teknik Mesin, Universitas Diponegoro, 2012 
Bekti Santoso, Ahdiat Leksi Siregar dan Indriana Lestari, Perhitungan Debit Uap Boiler dan Ketercapaian Kebutuhan Uap Pabrik Kapasitas 45 Ton/Jam, Jurnal Citra Widya Edukasi Vol XI No. 1 Agustus 2019. 